\title{
Authors
}

Donald Braman, Dan M. Kahan, Ellen Peters, Maggie Wittlin, Paul Slovic, Lisa Larrimore Ouellette, and Gregory N. Mandel 
Published version (linked):

Kahan, D.M., Peters, E., Wittlin, M., Slovic, P., Ouellette, L.L., Braman, D. \& Mandel, G. The polarizing impact of science literacy and numeracy on perceived climate change risks. Nature Climate Change 2, 732-735 (2012).

\section{The polarizing impact of science literacy and numeracy on perceived climate change risks}

\author{
Dan M. Kahan \\ Yale University \\ Maggie Wittlin \\ Cultural Cognition Project Lab \\ Donald Braman \\ George Washington University
}

\author{
Ellen Peters \\ The Ohio State University \\ Paul Slovic \\ Lisa Larrimore Ouellette \\ Decision Research \\ Cultural Cognition Project Lab \\ Gregory Mandel \\ Temple University
}

Acknowledgments. Research for this paper was funded by the National Science Foundation, Grant SES 0922714. Correspondence should be addressed to Dan M. Kahan, Yale Law School, PO Box 208215, New Haven, CT 06520. Email: dan.kahan@yale.edu.

D.M.K, E.P., M.W., and L.L.O. contributed to all aspects of the paper, including study design, statistical analysis, and writing and revisions. P.S., D.B., and G.M. contributed to the design of the study, to substantive analysis of the results, and to revisions of the paper. 
Seeming public apathy over climate change is often attributed to a deficit in comprehension. The public knows too little science, it is claimed, to understand the evidence or avoid being misled ${ }^{1}$. Widespread limits on technical reasoning aggravate the problem by forcing citizens to use unreliable cognitive heuristics to assess risk ${ }^{2}$. We conducted a study to test this account and found no support for it. Members of the public with the highest degrees of science literacy and technical reasoning capacity were not the most concerned about climate change. Rather, they were the ones among whom cultural polarization was greatest. This result suggests that public divisions over climate change stem not from the public's incomprehension of science but from a distinctive conflict of interest: between the personal interest individuals have in forming beliefs in line with those held by others with whom they share close ties and the collective one they all share in making use of the best available science to promote common welfare.

The study collected data on the climate-change risk perceptions of a large representative sample of U.S. adults $(N=1540)$. Measures were selected to permit assessment of two competing accounts of public opinion on climate change. One, already adverted to, can be called the "science comprehension thesis” (SCT): Because members of the public do not know what scientists know, or think the way scientists think, they predictably fail to take climate change as seriously as scientists believe they should ${ }^{3}$.

The alternative explanation can be referred to as the "cultural cognition thesis” (CCT). CCT posits that individuals, as a result of a complex of psychological mechanisms, tend to form perceptions of societal risks that cohere with values characteristic of groups with which they identify ${ }^{4-5}$. Whereas SCT emphasizes a conflict between scientists and the public, CCT stresses one between different segments of the public, whose members are motivated to fit their interpretations of scientific evidence to their competing cultural philosophies ${ }^{6}$.

Explanations for the public's perceptions of climate-change risk can be tested by observational study insofar as such hypotheses imply correlations between concern over climate change and specified individual characteristics ${ }^{7}$. We instructed subjects to rate their the seriousness of climate-change risk on a 
scale of 0 (“no risk”) to 10 (“extreme risk”), a general risk-concern measure that furnishes a parsimonious focus for such testing ${ }^{8-9}$.

SCT asserts, first, that ordinary members of the public underestimate the seriousness of climate change because of the difficulty of the scientific evidence ${ }^{3}$. If this is correct, concern over climate change should be positively correlated with science literacy—that is, concern should increase as people become more science literate.

Second, and even more important, SCT attributes low concern with climate change to limits on the ability of ordinary members of the public to engage in technical reasoning. Recent research in psychology posits two discrete forms of information processing: "System 1," which involves rapid visceral judgments that manifest themselves in various decision-making "heuristics"; and "System 2," which requires conscious reflection and calculation ${ }^{10}$. Most members of the public, according to this research, typically employ System 1 reasoning without resorting to more effortful System 2 processing. Although System 1 works well for most daily contingencies, citizens’ predominant reliance on heuristic rather than more analytic modes of reasoning is viewed as leading them to underestimate climate-change risks, which are remote and abstract compared to a host of more emotionally charged risks (e.g., terrorism) that the public is thought to overestimate ${ }^{2-3}$.

If this position is correct, one would also expect concern with climate change to be positively correlated with numeracy. Numeracy refers to the capacity of individuals to comprehend and make use of quantitative information ${ }^{11}$. More numerate people are more disposed to use accuracy-enhancing forms of System 2 reasoning and to be less vulnerable to the cognitive errors associated with System $1^{11-12}$. Hence, they should, on this view, form perceptions of climate-change risk less biased toward underestimation.

These predictions were unsupported (Fig. 1). As respondents' science-literacy scores increased, concern with climate change decreased $(r=-0.05, p=0.05)$. There was also a negative correlation between numeracy and climate-change risk $(r=-0.09, p<0.01)$. The differences were small, but nevertheless inconsistent with SCT, which predicts effects with the opposite signs. 

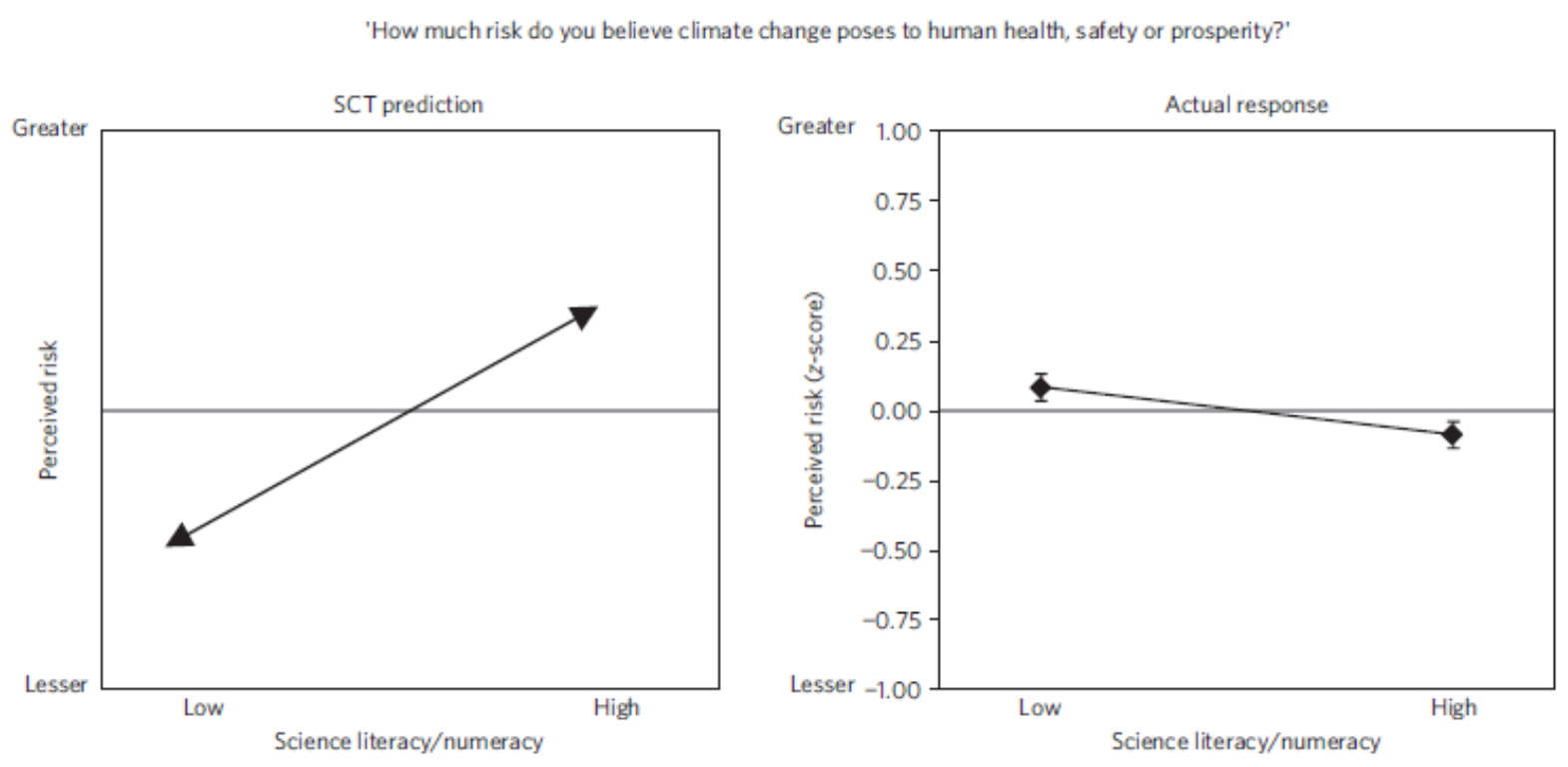

Fig. 1. SCT prediction vs. actual impact of science literacy and numeracy on climate-change risk perceptions.

Contrary to SCT predictions, higher degrees of science literacy and numeracy are associated with a small decrease in the perceived seriousness of climate-change risks. Derived from Table S4, Model 1. "Low" and "High" reflect values set at $-1 S D$ and $+1 S D$ on composite Science Literacy/Numeracy scale [see Supplementary Information (“SI”)]. Responses on 0-10 risk scale $(M=5.7, S D=3.4)$ converted to $z$-score to promote ease of interpretation. CIs reflect 0.95 level of confidence.

CCT also generates a testable prediction. CCT posits that persons who subscribe to a "hierarchical, individualistic” worldview—one that ties authority to conspicuous social rankings and eschews collective interference with the decisions of individuals possessing such authority—-tend to be skeptical of environmental risks. Such people intuitively perceive that widespread acceptance of such risks would license restrictions on commerce and industry, forms of behavior that Hierarchical Individualists value. In contrast, persons who hold an “egalitarian, communitarian” worldview—one favoring less regimented forms of social organization and greater collective attention to individual needs-tend to be morally suspicious of commerce and industry, to which they attribute social inequity. They therefore find it congenial to believe those forms of behavior are dangerous and worthy of restriction ${ }^{4}$. On this view, one would expect 
Egalitarian Communitarians to be more concerned than Hierarchical Individualists with climate change risks.

Our data, consistent with previous studies ${ }^{6}$, supported this prediction. "Hierarchical Individualists” (subjects who scored in the top half on both the Hierarchy and Individualism cultural-worldview scales) rated climate-change risks significantly lower $(M=3.15, S E M=0.17)$ than did Egalitarian Communitarians (subjects whose scores placed them in the bottom half) $(M=7.4$, $S E M=0.13)$. Even controlling for scientific literacy and numeracy (as reflected in the composite scale "Science Literacy/Numeracy”; see “Supplementary Information,” SI), both Hierarchy $(b=-0.46, p<0.01)$ and Individualism $(b=-0.30, p<0.01)$ predicted less concern over climate change (Table S4).

These findings were consistent, too, with previous ones showing that climate change has become highly politicized ${ }^{13-14}$. Cultural-worldview and political-orientation measures are modestly correlated. Nevertheless, the impact that cultural worldviews have on climate-change risk perceptions cannot be reduced to partisanship. The mean Hierarchical Individualist in our sample was an "Independent” who "leans Republican" and is "slightly conservative”; the mean Egalitarian Communitarian was also an "Independent," but one who "leans Democrat” and is "slightly liberal” (Fig. S4). The difference between their respective perceptions of climate-change risk, however, significantly exceeded what politicalorientation measures alone would predict for individuals who identify themselves as "conservative Republicans” and "liberal Democrats” (Fig. S5).

The finding that cultural worldviews explain more variance than science literacy and numeracy, however, does not by itself demonstrate that SCT is less supportable than CCT. SCT asserts not merely that members of the public lack scientific knowledge but also that they lack the habits of mind needed to assimilate it, and are thus constrained to rely on fallible heuristic alternatives. Proponents of this “bounded rationality” position treat cultural cognition—-the conforming of beliefs to the ones that predominate within one’s group - as simply one of the unreliable System 1 heuristics used to compensate for the inability to assess scientific information in a dispassionate, analytical manner. ${ }^{15}$ 
This claim generates another testable prediction. If cultural cognition is merely a heuristic substitute for scientific knowledge and System 2 reasoning, reliance on it should be lowest among those individuals whose scientific knowledge and System 2 reasoning capacity are highest. SCT thus implies that as science literacy and numeracy increase, the skepticism over climate change associated with a hierarchical individualistic worldview should lessen and the gap between people with hierarchical individualistic worldviews and those with egalitarian communitarian ones should diminish.
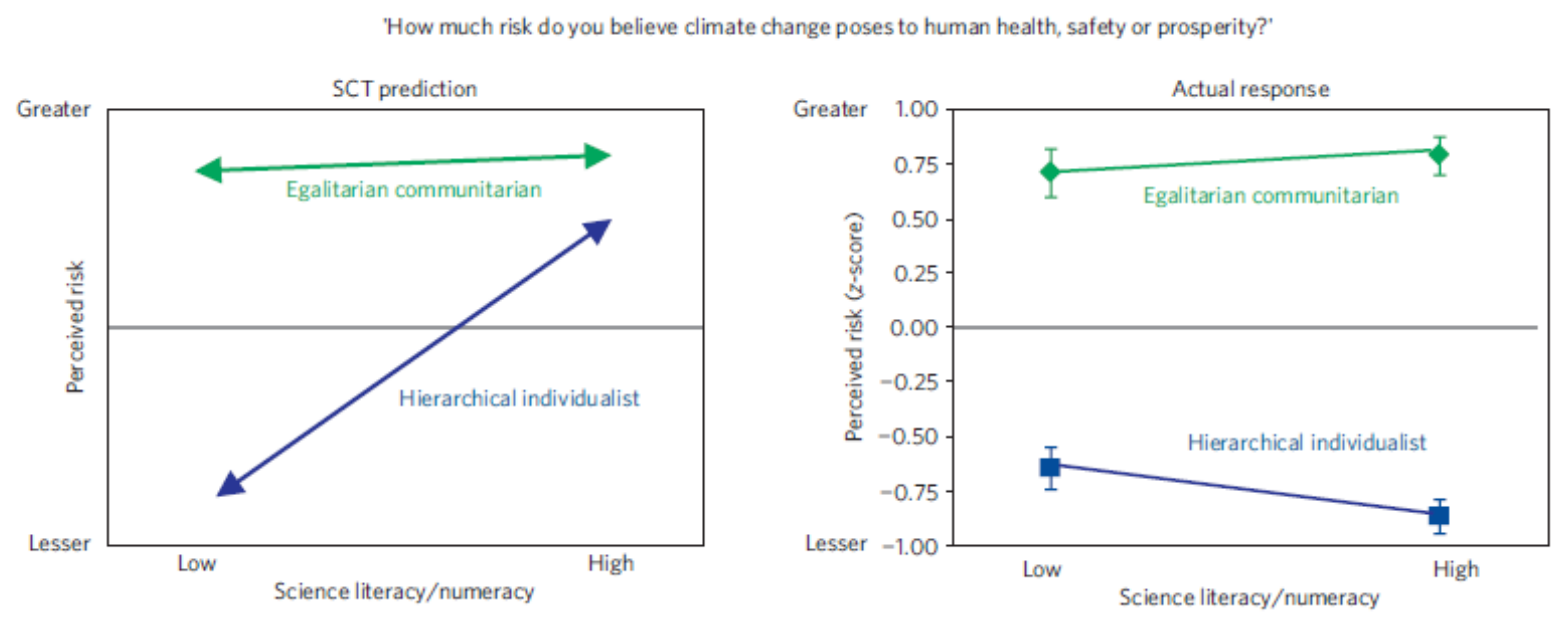

Fig. 2. SCT prediction vs. actual impact of the interaction between science literacy and numeracy, on the one hand, and cultural worldviews, on the other. Contrary to SCT's predictions, highly science-literate and numerate Hierarchical Individualists are more skeptical, not less, of climate-change risks. Estimated risk-perception scores derived from Table S4, Model 3. "Hierarchical Individualist” and "Egalitarian Communitarian” reflect values set, respectively, at +1 and $-1 S D$ on both the Hierarchy and Individualism cultural worldview scale predictors. "Low" and "high" reflect values set at -1 and $+1 S D$ on Science Literacy/Numeracy scale. Responses on 0-10 risk scale $(M=5.7, S D=3.4)$ converted to z-score to promote ease of interpretation. CIs reflect 0.95 level of confidence.

But this SCT prediction, too, was unsupported. Among Egalitarian Communitarians, science literacy and numeracy (as reflected in the composite scale "Science Literacy/Numeracy”), showed a small positive correlation with concern about climate-change risks $(r=0.08, p=0.03)$. But among Hierarchical Individualists, Science Literacy/Numeracy is negatively correlated with concern $(r=-0.12, p=0.03)$. Hence, polarization actually becomes larger, not smaller, as science literacy and numeracy increase (Fig. 
2; Table S4 \& Fig. S3). Because the contribution that culture makes to disagreement grows as science literacy and numeracy increase, it is not plausible to view cultural cognition as a heuristic substitute for the knowledge or capacities that SCT views the public as lacking.

To test the generality of this conclusion, we also analyzed subjects’ perceptions of nuclear-power risks. Egalitarian Communitarians and Hierarchical Individualists were again polarized. Moreover, here, too, the gap between subjects with these outlooks became larger, not smaller as scientific literacy and numeracy increased (Table S5; Fig. S3). Extending research that casts doubt on the "knowledge deficit" explanation ${ }^{16}$ for public controversy over climate-change and other environmental risks, these findings suggest that "bounded rationality" is an unsatisfactory explanation as well.

On the contrary, our findings could be viewed as evidence of how remarkably well equipped ordinary individuals are to discern which stances toward scientific information secure their personal interests. We will elaborate on this interpretation, which we offer as our own best provisional understanding of the results of this and related studies, but which we also believe warrants corroboration by experimental testing. We stress, too, that as consequential as cultural cognition is for disagreement over climate change, it does not imply the irrelevance of other, more general impediments to public engagement with climatechange science, including trust in communicators and the affective attenuation of risks seen by many as remote in time and place ${ }^{17}$.

For the ordinary individual, the most consequential effect of his beliefs about climate change is likely to be on his relations with his peers ${ }^{18}$. A Hierarchical Individualist who expresses anxiety about climate change might well be shunned by his coworkers at an oil refinery in Oklahoma City. A similar fate will likely befall the Egalitarian Communitarian English professor who reveals to colleagues in Boston that she thinks the "scientific consensus" on climate change is a "hoax." At the same time, neither the personal beliefs an ordinary person forms about scientific evidence nor any actions he takes-as a consumer, say, or democratic voter-will by itself aggravate or mitigate the dangers of climate change: On his own, he is just not consequential enough to matter ${ }^{19}$. Given how much the ordinary individual depends on peers for support—material and emotional—and how little impact his beliefs have on the physi- 
cal environment, he would likely be best off if he formed risk perceptions that minimized any danger of estrangement from his community.

A long-established body of work examining “motivated cognition”"20 supports this conjecture. Both to avoid dissonance and to secure their group standing, individuals unconsciously seek out and credit information supportive of "[s]elf-defining ... values [and] attitudes"21, such as the shared worldviews featured in the study of cultural cognition ${ }^{22}$. The predictive power of cultural worldviews implies that the average member of the public performs these tasks quite proficiently.

Our data, consistent with that observed in other settings ${ }^{23}$, suggest that those with the highest degree of science literacy and numeracy perform such tasks even more discerningly. Fitting information to identity-defining commitments makes demands on all manner of cognition—including both System 1 and System 2 reasoning ${ }^{19-20}$. For ordinary citizens, the reward for acquiring greater scientific knowledge and more reliable technical-reasoning capacities is a greater facility to discover and use-or explain awayevidence relating to their groups’ positions.

Even if cultural cognition serves the personal interests of individuals, this form of reasoning can have a highly negative impact on collective decision making. What guides individual risk perception, on this account, is not the truth of those beliefs but rather their congruence with individuals' cultural commitments. As a result, if beliefs about a societal risk such as climate change come to bear meanings congenial to some cultural outlooks but hostile to others, individuals motivated to adopt culturally congruent risk perceptions will fail to converge, or at least fail to converge as rapidly as they should, on scientific information essential to their common interests in health and prosperity. Although it is effectively costless for any individual to form a perception of climate-change risk that is wrong but culturally congenial, it is very harmful to collective welfare for individuals in aggregate to form beliefs this way.

One aim of science communication, we submit, should be to dispel this tragedy of the riskperception commons ${ }^{24}$. A communication strategy that that focuses only on transmission of sound scientific information, our results suggest, is unlikely to do that. As worthwhile as it would be, simply improv- 
ing the clarity of scientific information will not dispel public conflict so long as the climate-change debate continues to feature cultural meanings that divide citizens of opposing worldviews.

It does not follow, however, that nothing can be done to promote constructive and informed public deliberations. Because citizens understandably tend to conform their beliefs about societal risk to beliefs that predominate among their peers, communicators should endeavor to create a deliberative climate in which accepting the best available science does not threaten any group's values. Effective strategies include use of culturally diverse communicators, whose affinity with different communities enhances their credibility, and information-framing techniques that invest policy solutions with resonances congenial to diverse groups ${ }^{22}$. Perfecting such techniques through a new science of science communication is a public good of singular importance ${ }^{25}$.

Methods. Study subjects consisted of a nationally representative general population sample of 1540 Americans who participated in the study via the on-line testing facilities of Knowledge Networks. Knowledge Networks (http://www.knowledgenetworks.com/) is a public opinion research firm with offices located throughout the United States. It maintains an active respondent pool of some 50,000 adults who are recruited to participate in online surveys and experiments administered on behalf of academic and governmental researchers and private businesses. Its recruitment and sampling methods assure a diverse sample that is demographically representative of the U.S. population.

We measured respondents' values using scales associated with studies of the "cultural theory of risk”4-5. The first, Hierarchy-Egalitarianism ("Hierarchy”), consists of “agree-disagree” items that indicate attitudes toward social orderings that connect authority to stratified social roles based on highly conspicuous and largely fixed characteristics such as gender, race, and class ("We need to dramatically reduce inequalities between the rich and the poor, whites and people of color, and men and women”). Items from the second scale, Individualism-Communitarianism (“Individualism”), express attitudes toward social orderings in which the individual is expected to secure his or her own well-being without assistance or interference from society versus ones in which society is obliged and empowered to secure collective wel- 
fare in the face of competing individual interests (e.g., "Government should put limits on the choices individuals can make so they don't get in the way of what's good for society”).

We measured respondents' “science literacy” with National Science Foundation’s “Science and Engineering Indicators"26. Focused on physics and biology (e.g., "Electrons are smaller than atoms [true/false]”; “Antibiotics kill viruses as well as bacteria [true/false]”), the NSF Indicators are widely used as an index of public comprehension of basic science ${ }^{27}$.

We measured subjects' “numeracy” — their capacity to comprehend and use quantitative information-with fourteen mathematical word problems ${ }^{11,28-29}$ (e.g., "A bat and a ball cost $\$ 1.10$ in total. The bat costs $\$ 1.00$ more than the ball. How much does the ball cost?”). We combined responses to the NSF Indicators and the numeracy questions into a composite scale $(\alpha=0.85)$, labeled "Science Literacy/Numeracy,” to avoid collinearity in multivariate analyses of their association with respondents' risk perceptions $^{30}$.

Those risk perceptions were measured with GWRISK and NUKERISK, which asked respondents to indicate "How much risk" they believed "climate change” and "nuclear power," respectively, "pose[] to human health, safety, or prosperity” on a 0 (“no risk”) to 10 (“extreme risk”) scale. Risk-perception items that conform to this format are known to elicit responses that correlate highly with ones targeted at more specific factual beliefs about the hazards of putative risk sources and are thus routinely used as a parsimonious focus for analysis of variance in risk perceptions ${ }^{8-9}$.

Study hypotheses were tested by ordinary least squares linear regression (Table S4 \& Table S5). Predictors included the cultural worldview scales, Science Literacy/Numeracy, and appropriate crossproduct interaction terms. To promote visual comprehension of the variance associated with various predictors, responses to GWRISK $(M=5.7, S D=3.4)$ and NUKERISK $(M=6.1, S D=3.0)$ were transformed into z-scores.

Full item wording for all measures and the multivariate regression outputs are reported in the online Supplementary Information. 


\section{References and Notes}

1. Pidgeon, N., \& Fischhoff, B. (2011). The role of social and decision sciences in communicating uncertain climate risks. Nature Clim. Change, 1(1), 35-41.

2. Sunstein, C.R. On the divergent American reactions to terrorism and climate change. Columbia L. Rev. 107, 503-57 (2007).

3. Weber, E.U. \& Stern, P.C. Public understanding of climate change in the United States. Am. Psychologist 66, 315-328 (2011).

4. Douglas, M. \& Wildavsky, A.B. Risk and culture: An essay on the selection of technical and environmental dangers (University of California Press, Berkeley, 1982).

5. Kahan, D.M., Braman, D., Slovic, P., Gastil, J. \& Cohen, G. Cultural cognition of the risks and benefits of nanotechnology. Nature Nanotechnology 4, 87-91 (2009).

6. Kahan, D.M., Jenkins-Smith, H. \& Braman, D. Cultural cognition of scientific consensus. J. Risk Res. 14, 147-174 (2011)..

7. Pearl, J. Causality: Models, reasoning, and inference (Cambridge University Press, Cambridge, U.K. 2009).

8. Dohmen, T., Falk, A., Huffman, D., Sunde, U., Schupp, J. \& Wagner, G.G. Individual risk attitudes: Measurement, determinants, and behavioral consequences. Journal of the European Economic Association 9, 522-550 (2011).

9. Ganzach, Y., Ellis, S., Pazy, A. \& Tali. On the perception and operationalization of risk perception. Judgment and Decision Making 3, 317-324 (2008).

10. Kahneman, D. Maps of Bounded rationality: Psychology for behavioral economics. Am. Econ. Rev. 93, 1449 (2003).

11. Peters, E., Västfjäll, D., Slovic, P., Mertz, C. K., Mazzocco, K., \& Dickert, S. Numeracy and decision making. Psychol. Sci. 17, 407-413 (2006).

12. Liberali, J.M., Reyna, V.F., Furlan, S., Stein, L.M. \& Pardo, S.T. Individual differences in numeracy and cognitive reflection, with implications for biases and fallacies in probability judgment. Journal of behavioral decision making. J. Behav. Decision Making (2011), advance on-line publication at http://doi.10.1002/bdm.752.

13. McCright, A.M. \& Dunlap, R.E. Cool dudes: The denial of climate change among conservative white males in the United States. Global Environmental Change 21, 1163-1172 (2011).

14. Krosnick, J.A., Holbrook, A.L. \& Visser, P.S. The impact of the fall 1997 debate about global warming on American public opinion. Public Understanding of Science 9, 239-260 (2000).

15. Sunstein, C.R. Misfearing: A reply. Harv. L. Rev. 119, 1110-25 (2006).

16. Kellstedt, P.M., Zahran, S. \& Vedlitz, A. Personal efficacy, the information environment, and attitudes toward global warming and climate change in the United States. Risk Analysis 28, 113-126 (2008).

17. Slovic, P. Trust, Emotion, sex, politics, and science: Surveying the risk-assessment battlefield. Risk Analysis 19, 689-701 (1999). 
18. Cohen, G.L. Party over policy: The dominating impact of group influence on political beliefs. $J$. Personality \& Soc. Psych. 85, 808-22 (2003).

19. Downs, A. An economic theory of democracy (Harper, New York,, 1957).

20. Chen, S., Duckworth, K. \& Chaiken, S. Motivated heuristic and systematic processing. Psychol. Inq. 10, 44-49 (1999).

21. Giner-Sorolla, R. Chaiken, S. Selective use of heuristic and systematic processing under defense motivation. Personality \& Social Psychol. Bull. 23, 84 (1997), p. 85.

22. Kahan, D. Fixing the communications failure. Nature 463, 296-97 (2010).

23. Mercier, H. \& Sperber, D. Why do humans reason? Arguments for an argumentative theory. Behavioral and Brain Sciences 34, 57-74 (2011).

24. Hardin, G. The tragedy of the commons. Science 162, 1243-48 (1968).

25. Nisbet, M.C. Framing science: A new paradigm of public engagement. In Communicating science: New agendas in communication 41-67 (Routledge, New York, 2010).

26. National Science Board. Science and engineering indicators, 2010. (National Science Foundation, Arlington, Va., 2010).

27. Allum, N., Sturgis, P. Tabourazi, D. \& Brunton-Smith, I.. Science knowledge and attitudes across cultures: a meta-analysis. Public Understanding of Science 17, 35-54 (2008).

28. Weller, J., Dieckmann, N.F., Tusler, M., Mertz, C.K., Burns, W., \& Peters, E. Development and testing of an abbreviated numeracy scale: A rasch analysis approach Journal of Behavioral Decision Making (in press).

29. Frederick, S. Cognitive reflection and decision making. J. Econ. Perspectives 19, 25-42 (2005).

30. Berry, W.D. \& Feldman, S. Multiple regression in practice. Sage university papers series. Quantitative applications in the social sciences no. 07-050 (Sage Publications, Beverly Hills, 1985), p. 48. 


\section{The polarizing impact of science literacy and numeracy on perceived climate change risks}

1. Information on sample

The sample for this survey, conducted in January 2010, was 52\% female, $76 \%$ white, and $8 \%$ African-American. The average age was 47 years. The median household income for the sample was $\$ 50,000-\$ 59,000$. The median educational level was "some college."

\section{Statistical power}

The anticipated statistical analyses required a relatively large sample. Inferences drawn from the absence of hypothesized effects (or the existence of hypothesized null effects), moreover, present a significant risk of Type II error in underpowered studies ${ }^{1}$. In addition, interactions between individual characteristics such as cultural values and science literacy or numeracy tend to be small and thus to evade detection in observational studies with modest-sized samples ${ }^{2}$. The sample size used in this study was sufficient to detect the significance (at $p<0.05$ ) of even "small" effects (e.g., $r=0.10$ ) at a power exceeding the conventional 0.80 cutoff $^{2,3}$.

\section{Measures}

a. Cultural worldviews. Subjects' cultural values or "worldviews" were measured with items used in previous studies of cultural cognition ${ }^{4-5}$. These items characterize worldviews along two cross-cutting dimensions: Hierarchy-Egalitarianism ("Hierarchy") and Individualism-Communitarianism ("Individualism") (Table S1). The former set of items indicate attitudes toward social orderings that connect authority to stratified social roles based on highly conspicuous and largely fixed characteristics 
such as gender, race, and class. The latter indicate attitudes toward social orderings that reflect an expectation that individuals will secure their own well-being without assistance or interference from society versus those that assign society the obligation to secure collective welfare and the power to override competing individual interests. For all items, subjects indicated agreement or disagreement on a six-point scale.

\section{Cultural Cognition of Risk}

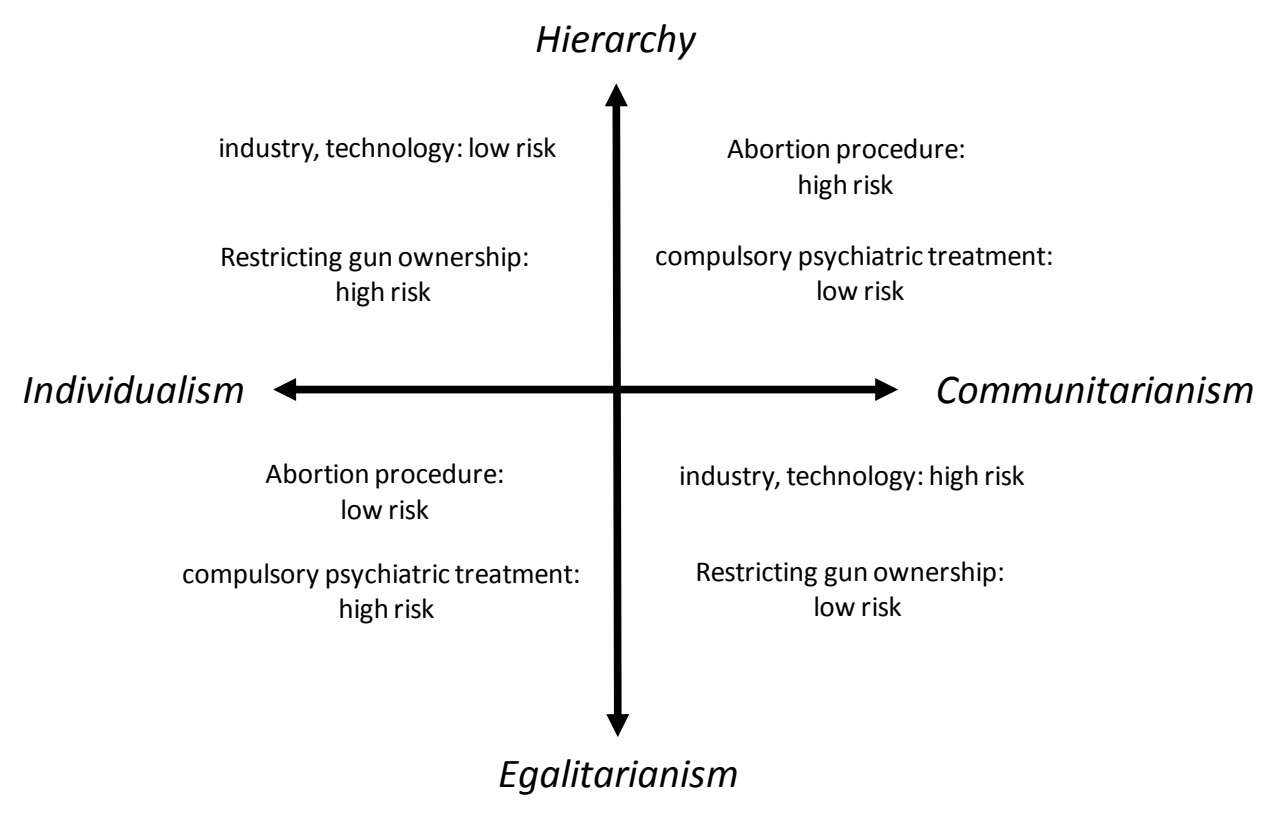

Fig. S1. Cultural cognition of risk. Studies of the cultural cognition of risk relate information-processing to cultural worldviews. Worldviews—essentially preferences for how society and other collective undertakings should be organized—are measured with two scales: "Hierarchy-Egalitarianism” and "Individualism-Communitarianism.” The theory on which cultural cognition is based posits that perceptions of environmental and technological risks should be expected to diminish as worldviews become simultaneously more hierarchical and individualistic, and increase as worldviews become simultaneously more egalitarian and communitarian. Other types of risks, including ones relating to public health and social deviance, can be expected to vary more dramatically as worldviews become progressively more hierarchical and communitarian or progressively more egalitarian and individualistic. Survey and experimental studies have found support for these predictions ${ }^{4-8}$. 
For this study, we used short-form versions of Hierarchy and Individualism (Table S1), each of which consisted of six items ${ }^{9}$. Like the full-form versions, the two six-item sets formed reliable scales (Hierarchy, $\alpha=0.84$; Individualism, $\alpha=0.76$ ), the items of which loaded appropriately on two separate factors, which were labeled "Hierarchy” and "Individualism” and used as predictors for the study.

Individualism-Communitarianism (Individualism)

IINTRSTS. The government interferes far too much in our everyday lives.

Sometimes government needs to make laws that keep people from hurting

CHARM. themselves.

IPROTECT. It's not the government's business to try to protect people from themselves.

IPRIVACY. The government should stop telling people how to live their lives.

The government should do more to advance society's goals, even if that means

CPROTECT. limiting the freedom and choices of individuals.

Government should put limits on the choices individuals can make so they don't get

CLIMCHOI. in the way of what's good for society.

\section{Hierarchy-Egalitarianism (Hierarchy)}

HEQUAL. We have gone too far in pushing equal rights in this country.

EWEALTH. Our society would be better off if the distribution of wealth was more equal.

We need to dramatically reduce inequalities between the rich and the poor, whites and

ERADEQ. people of color, and men and women.

EDISCRIM. Discrimination against minorities is still a very serious problem in our society.

It seems like blacks, women, homosexuals and other groups don’t want equal rights,

HREVDIS2. they want special rights just for them.

HFEMININ. Society as a whole has become too soft and feminine.

\section{Table S1. Cultural-worldview items.}

b. Numeracy. Respondents' numeracy-their proficiency in understanding quantitative information and engaging in mathematical reasoning ${ }^{10-13}$ — was measured with a set of 14 questions used in previous studies (Table S2). Item responses formed a reliable scale $(\alpha=0.85)$, which was labeled “Numeracy." 
EVENROLL.

PCTTOFREQUENCY1.

FREQUENCYTOPCT1.

COMPFREQUENCY.

СOMPPCT.

DOUBLEPCT.

DOUBLEFREQUENCY.

PCTTOFREQUENCY2.

A:

B:

FREQUENCYTOPCT2.

VIRAL.

BAYESIAN.

SHANE1.

SHANE2.
Imagine that we roll a fair, six-sided die 1,000 times. (That would mean that we roll one die from a pair of dice.) Out of 1,000 rolls, how many times do you think the die would come up as an even number?

In the BIG BUCKS LOTTERY, the chances of winning a $\$ 10.00$ prize are $1 \%$. What is your best guess about how many people would win a $\$ 10.00$ prize if 1,000 people each buy a single ticket from BIG BUCKS?

In the ACME PUBLISHING SWEEPSTAKES, the chance of winning a car is 1 in 1,000. What percent of tickets of ACME PUBLISHING SWEEPSTAKES win a car?

Which of the following numbers represents the biggest risk of getting a disease?

Which of the following numbers represents the biggest risk of getting a disease?

If Person A's risk of getting a disease is $1 \%$ in ten years, and Person B's risk is double that of A's, what is B's risk?

If Person A's chance of getting a disease is 1 in 100 in ten years, and person $\mathrm{B}$ 's risk is double that of A, what is B's risk?

If the chance of getting a disease is $10 \%$, how many people would be expected to get the disease:

Out of $100 ?$

Out of 1000 ?

If the chance of getting a disease is 20 out of 100 , this would be the same as having a _ $\%$ chance of getting the disease.

The chance of getting a viral infection is .0005 . Out of 10,000 people, about how many of them are expected to get infected?

Suppose you have a close friend who has a lump in her breast and must have a mammogram. Of 100 women like her, 10 of them actually have a malignant tumor and 90 of them do not. Of the 10 women who actually have a tumor, the mammogram indicates correctly that 9 of them have a tumor and indicates incorrectly that 1 of them does not have a tumor. Of the 90 women who do not have a tumor, the mammogram indicates correctly that 81 of them do not have a tumor and indicates incorrectly that 9 of them do have a tumor. The table below summarizes all of this information. Imagine that your friend tests positive (as if she had a tumor), what is the likelihood that she actually has a tumor?

A bat and a ball cost $\$ 1.10$ in total. The bat costs $\$ 1.00$ more than the ball. How much does the ball cost?

In a lake, there is a patch of lilypads. Every day, the patch doubles in size. If it takes 48 days for the patch to cover the entire lake, how long would it take for the patch to cover half of the lake? 
Numeracy was weakly associated with cultural outlooks. The correlation between Numeracy and Hierarchy was 0.14 , and between Numeracy and Individualism was -0.07 ( $p<.01$, in both cases). For Hierarchical Individualists, the mean score was $8.0(S E M=0.15)$, and for Egalitarian Communitarians 7.5 $(S E M=0.18)$.

c. Science literacy. To measure science literacy, subjects were asked a set of questions drawn from the National Science Foundation's “Science and Engineering Indicators”"14. The indicators have been widely used over a long period of time and across a large number of societies as an index of public comprehension of basic science $^{15}$. We included eight NSF Indicator items in the survey (Table S3). The mean number of correct responses was $5.9(S D=1.86)$. Responses formed a modestly reliable scale $(\alpha=0.62)$, which was labeled Sciliteracy. There was a small but significant positive correlation between this variable and Hierarchy ( $r=0.09, p<0.01$ ), and a small, nonsignificant one between it and Individualism $(r=0.03, p=0.17)$. The mean Sciliteracy score was $6.3(S E M=0.09)$ for Hierarchical Individualists, and $6.0(S E M=0.10)$ for Egalitarian Communitarians.

\begin{tabular}{llr} 
items & & $\%$ correct \\
\hline EARTHOT & The center of the Earth is very hot [true/false]. & $86 \%$ \\
HUMANRADIO & All radioactivity is man-made [true/false]. & $84 \%$ \\
LASERS & Lasers work by focusing sound waves [true/false]. & $68 \%$ \\
ELECATOM & Electrons are smaller than atoms [true/false]. & $62 \%$ \\
COPERNICUS1 & Does the Earth go around the Sun, or does the Sun go around the Earth? \\
COPERNICUS2 & How long does it take for the Earth to go around the Sun? [one day, one month, one year] \\
DADGENDER & It is the father's gene that decides whether the baby is a boy or a girl [true/false]. & $72 \%$ \\
ANTIBIOTICS & Antibiotics kill viruses as well as bacteria [true/false]. & $45 \%$ \\
\hline
\end{tabular}

Table S3. Science literacy items. $N=1540$. Consistent with the NSF Science Indicators scoring method, COPERNICUS2 was administered only to subjects who correctly answered COPERNICUS1.

\section{Multivariate analyses}

We performed two sets of multivariate regression analyses to test the various hypotheses associated with SCT. The outcome variables were GWRISK and NUKERISK, which asked respondents to indicate "How much risk" they believed "climate change” and "nuclear power,” respectively, "pose[] 
to human health, safety, or prosperity” on a 0 (“no risk”) to 10 (“extreme risk”) scale. To improve visual comprehension of the variance associated with various predictors, responses to GWRISK $(M=5.7$, $S D=3.4)$ and NUKERISK $(M=6.1, S D=3.0)$ were transformed into $z$-scores.

We combined Sciliteracy and Numeracy into a composite scale $(\alpha=0.85)$, labeled "Science Literacy/Numeracy,” to avoid collinearity in analyses of their association with the outcome variables ${ }^{16}$. The z-score transformation of Science Literacy/Numeracy (z_Sci/Num) was used as a predictor in the regression analyses in order to center the variable at 0 and thereby enhance the interpretability of models with cross-product interaction terms. In addition, cross-product variables ("Hierarch x z_Sci/Num” and “Individ x z_Sci/Num”) were constructed to test for interactions between Science Literacy/Numeracy and the two worldview measures ${ }^{17}$.

\begin{tabular}{|c|c|c|c|c|c|c|}
\hline \multicolumn{7}{|c|}{ Climate Change } \\
\hline & \multicolumn{2}{|c|}{ Model 1} & \multicolumn{2}{|c|}{ Model 2} & \multicolumn{2}{|c|}{ Model 3} \\
\hline z_Sci/Num & -0.09 & $(-3.35)$ & -0.03 & $(-1.43)$ & -0.04 & $(-1.70)$ \\
\hline Hierarch & & & -0.46 & $(-21.06)$ & -0.46 & $(-20.41)$ \\
\hline Individ & & & -0.30 & $(-13.97)$ & -0.30 & $(-13.57)$ \\
\hline Hierarch x z_Sci/Num & & & & & -0.05 & $(-2.30)$ \\
\hline Individ x z_Sci/Num & & & & & -0.02 & $(-1.12)$ \\
\hline Constant & 0.00 & $(-0.02)$ & 0.00 & $(0.00)$ & 0.00 & $(0.14)$ \\
\hline$R^{2}$ & 0.01 & & 0.30 & & 0.31 & \\
\hline$F$ & $(1,1538)$ & 11.23 & $(3,1536)$ & 221.99 & $(5,1534)$ & 134.62 \\
\hline$\Delta F$ & & & $(2,1536)$ & 320.73 & $(2,1537)$ & 3.10 \\
\hline
\end{tabular}

Table S4. Multivariate regression analysis of climate change risk perceptions. $N=1540$. The effects of the model predictors are expressed in unstandardized OLS regression coefficients with $t$-statistic indicated parenthetically. The outcome variable is the standardized (z-score) response to GWRISK. Bolded indicates that the coefficient, F-statistic, or the change in $F$-statistic is significant at $p<0.05$. Note that because all predictors are centered at 0 , the regression coefficients for the predictor and moderator variables in models that contain crossproduct interaction terms indicate the effect of the relevant variable when the other is at its mean value ${ }^{17}$. Missing values for individual cultural-worldview items and for GWRISK were replaced using multiple imputation ${ }^{18}$. 
Sequential models were used to test the impact of Science Literacy/Numeracy, the cultural worldviews, and the interactions of these variables. In the first step, risk perceptions were regressed on Science Literacy/Numeracy alone, which predicted less concern for both climate-change (Table S4, Model 1) and nuclear risk perceptions (Table S5, Model 1).

The cultural-worldview variables were entered next. Both Hierarchy and Individualism predicted less concern for the two forms of risk perception (Table S4, Model 2; Table S5, Model 2).

The analyses associated with Model 2 show the impact of the cultural outlooks controlling for differences in the level of science literacy and numeracy. The large and statistically significant impact of the worldview predictors thus confirms that the contribution they make to variance in perceptions of climate change risk is not a consequence of differences in science literacy or numeracy levels among subjects with one or the other of these worldviews.

In the final step, variables to test for the interaction between science literacy and numeracy, on the one hand, and the cultural-worldview variables, on the other, were added to the analyses (Table S4, Model 3; Table S5, Model 3). In both models, the coefficients for the cross-product terms are negative (indicating that the impact of Hierarchy and Individualism in reducing climate-change and nuclear-power risk perceptions increases as Sci/Num increases). Although only one of the individual cross-product interaction terms is significant on its own in each analysis, the combined effect of the cross-product interaction terms as a set was significant for both, as confirmed by the significance change in $F$-statistic in Model 3 of the respective analyses ${ }^{19}$. The joint effect sizes of these interactions were in line with ones commonly detected in observational studies². 
Nuclear Power

\begin{tabular}{|c|c|c|c|c|c|c|}
\hline & \multicolumn{2}{|c|}{ Model 1} & \multicolumn{2}{|c|}{ Model 2} & \multicolumn{2}{|c|}{ Model 3} \\
\hline z_Sci/Num & -0.30 & $(-12.06)$ & -0.27 & $(-11.18)$ & -0.28 & $(-11.40)$ \\
\hline Hierarch & & & -0.24 & $(-9.82)$ & -0.23 & $(-9.28)$ \\
\hline Individ & & & -0.12 & $(-4.86)$ & -0.11 & $(-4.59)$ \\
\hline Hierarch x z_Sci/Num & & & & & -0.04 & $(-1.59)$ \\
\hline Individ x z_Sci/Num & & & & & -0.05 & $(-2.31)$ \\
\hline Constant & 0.00 & $(0.03)$ & 0.00 & $(-0.05)$ & 0.00 & $(0.09)$ \\
\hline$R^{2}$ & 0.09 & & 0.15 & & 0.16 & \\
\hline$F$ & $(1,1538)$ & 145.34 & $(3,1536)$ & 91.39 & $(5,1534)$ & 56.48 \\
\hline$\Delta F$ & & & $(2,1536)$ & 59.44 & $(2,1537)$ & 3.80 \\
\hline
\end{tabular}

Table S5. Multivariate regression analyses of nuclear power risk perceptions. $N=1540$. The effects of the model predictors are expressed in unstandardized OLS regression coefficients with $t$-statistic indicated parenthetically. The outcome variable is the standardized (z-score) response to NUKERISK. Bolded indicates that the coefficient, $F$-statistic, or the change in $F$-statistic is significant at $p<0.05$. Note that because all predictors are centered at 0 , the regression coefficients for the predictor and moderator variables in models that contain crossproduct interaction terms indicate the effect of the relevant variable when the other is at its mean value ${ }^{17}$. Missing values for individual cultural-worldview items and for NUKERISK were replaced using multiple imputation ${ }^{18}$.

Because the impact of even the nonsignificant predictors can result in a significant effect when aggregated consistent with study hypotheses, the most straightforward and informative means to test the hypotheses is to use the regression model to estimate the impact (including confidence intervals) of relevant combinations of predictors ${ }^{20-21}$. Such estimates, based on Model 3 of the respective regression analyses, are reported graphically in Fig. S2. The results confirm the lack of support for the conclusion that science literacy and numeracy predict increased risk concern for climate-change risk perceptions. The results also confirm that the cultural-worldview variables predict both sets of risk perceptions independently of science literacy and numeracy (that is, when Science Literacy/Numeracy is controlled for by being set to its mean).

Finally, they demonstrate that as science literacy and numeracy (as reflected in Science Literacy/Numeracy) increase, cultural polarization increases for both climate-change risk perceptions and nuclear-power risk perceptions (Fig. S3). Higher levels of science literacy and numeracy predict a more 
substantial abatement of concern over nuclear-power risks $(b=0.30, p<0.01)$ than over climate-change risk $(b=-0.09, p<0.01)$. This effect, however, is significantly more pronounced among subjects whose worldviews are hierarchical and individualist than among those whose worldviews are egalitarian and communitarian (Fig. S3). Thus, for nuclear-power risk perceptions, as for climate-change risk perceptions, polarization grows as science literacy and numeracy increase (Fig. S3).
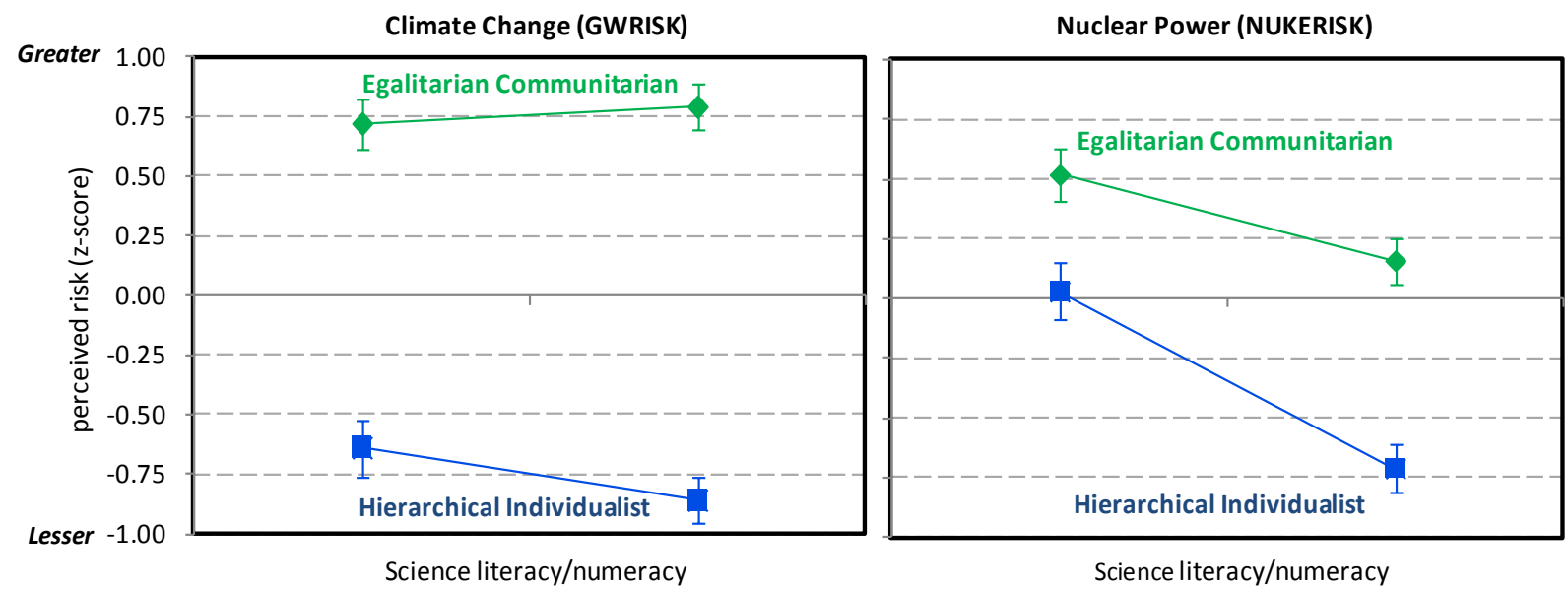

Fig. S2. Impact of the interaction between science literacy and numeracy, on the one hand, and cultural worldviews, on the other, for climate-change and nuclear-power risk perceptions. $N=1540$. Derived from regression analysis reported in Table S4, Model 3, and Table S5, Model 3. "Hierarchical individualist" and "Egalitarian communitarian" reflect values set, respectively, at $+1 S D$ and $-1 S D$ on both the Hierarchy and Individualism cultural-worldview scale predictors. "Low" and "high" reflect values set at $-1 S D$ and $+1 S D$ on Science/Numeracy scale, a composite scale based on respondents' science literacy and numeracy scores. Responses on 0-10 risk scales (GWRISK: $M=5.7, S D=3.4$; NUKERISK: $M=6.1, S D=3.0$ ) were converted to z-scores to promote ease of interpretation. CIs reflect 0.95 level of confidence. 


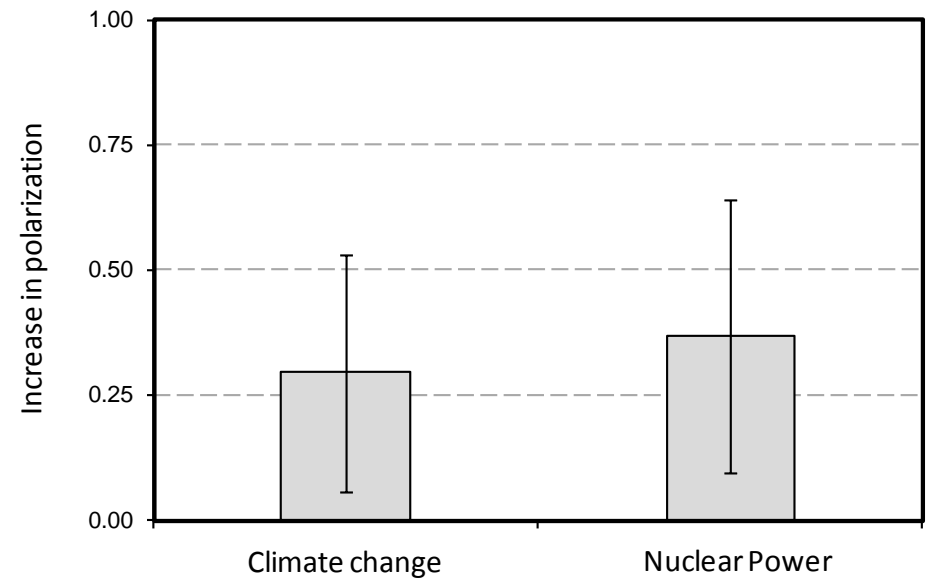

Fig. S3. Multivariate regression estimates of increased polarization associated with increased numeracy and science literacy. Estimates derived from Model 3 of the regression outputs reported in Table S4 \& Table S5, respectively. Bars indicate how much larger cultural polarization is when science-literacy and numeracy are high as opposed to low. The estimates are derived by comparing how much larger the difference in the estimated values of the outcome variable between "Hierarchical Individualist" (+1 SD on both worldview scales) and "Egalitarian Communitarian” (-1 SD on both scales) are when (1) the predictor value for Science Literacy/Numeracy is set at a "high" value $(+1 S D)$ than it is when (2) the predictor value for Science Literacy/Numeracy is set at a "low" value (-1 SD), with product-interaction term values being correspondingly. CIs indicate 0.95 level of confidence.

\section{Political-orientation measures compared to cultural-worldview ones}

We also collected data on our subjects' political orientations. For this purpose, we used two items: REPUB, a 7-point measure (“Strong Democrat, Democrat, Leans Democrat, Independent/other, Leans Republican, Republican, and Strong Republican”) of partisan self-identification ( $M=3.72$, $S D=2.13$ ); and CONSERV, a 7-point measure ("Strongly Liberal, Liberal, Weakly Liberal, Middle of the Road, Weakly Conservative, Conservative, or Strongly Conservative”) of self-reported liberalconservative ideology $(M=4.13, S D=1.49)$. We present analyses intended to enable readers and researchers who are more familiar with or who otherwise prefer political-orientation measures to assess our findings. 
a. Political orientations in relation to cultural worldviews. In the main text, we report means and regression estimates for the "typical Egalitarian Communitarian" and the "typical Hierarchical Individualist.” As an expositional device—one that identifies the subsets of study respondents in whom sample-wide variance is most strongly concentrated-this is equivalent to reporting similar data for subsamples who self-identify as "Republicans" and "Democrats" or as "liberals" and "conservatives" when political orientation measures are used to analyze variance (e.g., Krosnick, Holbrook, \& Visser 2000).

The cultural-worldview measures are moderately correlated with the political orientation measures. Thus, in our sample both Hierarchy $(r=0.48, p<0.01)$ and Individualism $(r=0.23, p<0.01)$ are positively correlated with REPUB. Both are also positively correlated with CONSERV (Hierarchy: $r=0.47, p<0.01$; Individualism, $r=0.23, p<0.01$ ).

Nevertheless, in our sample, subjects whom we would characterize as "Egalitarian Communitarians" and "Hierarchal Individualists" (based on the relationship of their Hierarchy and Individualism scores to the means on the worldview scales) are more moderate in their political orientations than the ones who self-identify as "Democrat" or "Republican," or as "liberal" or “conservative” without qualification (Fig. S4). The mean REPUB and CONSERV scores of Hierarchical Individualists $(M=5.18, S E M=0.09 ; M=5.10, S E M=0.06$, respectively) equate approximately to an “Independent or other” who "leans Republican” and who is "slightly conservative.” Scores of Egalitarian Communitarians $(M=2.60, S E M=0.09 ; M=3.34, S E M=0.08$, respectively) equate approximately to an "Independent or other” who "leans Democrat” and who is "slightly Liberal. 

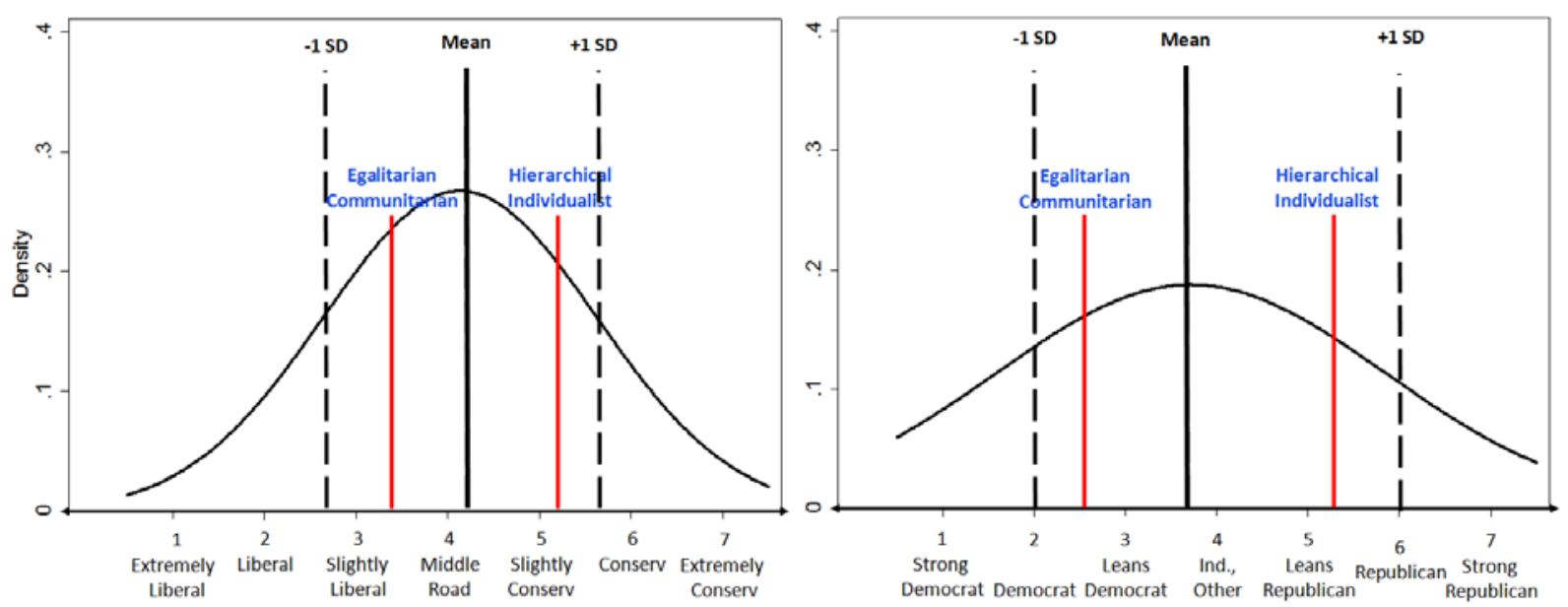

Fig. S4. Relation of cultural outlooks to political orientations. Figures plot normal-density distributions for respones to CONSERV $(M=4.13, S D=1.49)$ and REPUB $(M=3.71, S D=2.13)$. Red lines indicate the mean scores on the indicated measures for subjects classified as either Egalitarian Communitarian or Hierarchal Individualist (based on the relationship of their Hierarchy and Individualism scores to the means on the worldview scales). The solid black line indicates the sample mean, and the dotted red lines the values for \pm 1 standard deviation, on each scale.

b. Explanatory power for climate-change risk perceptions. Table S6 reports parallel multivariate regressions in which the political-orientation measures and cultural-worldview measures are treated as predictors of climate-change risk perceptions. Differences in political orientation, the analyses suggests, generate less disagreement in climate-change risk perceptions than do comparable differences in cultural worldview. Specifically, the estimated difference in the z_GWRISK scores when the values for REPUB and CONSERV predictors were both set at -1 SD (illustrative values for a typical "Liberal Democrat"), on the one hand, and $+1 S D$ (values for a typical "Conservative Republican”), on the other, was 1.09 ( $t$ statistic $=-21.93, p<0.01)$. The estimated difference in the z_GWRISK scores when the values for Hierarchy and Individualism predictors were both set at -1 SD (illustrative values for a typical "Egalitarian Communitarian”), on the one hand, and +1 SD (values for a typical "Hierarchical Conservative”), on the other, was 1.54 ( $t$-statistic $=-25.15, p<0.01)$. 
When the values for REPUB and CONSERV were set at levels corresponding to the scores of the average Hierarchical Individualist (5.18 and 5.10) and Egalitarian Communitarian (2.60 and 3.34), the predicted difference in risk perceptions was even more modest $(\Delta E M=-0.66, t$-statistic $=22.02, p<$ 0.01). A model based only on political orientation predictors, then, would thus substantially underestimate the degree of polarization that exists between typical Hierarchical Individualists, on the one hand, and the typical Egalitarian Communitarians, on the other (Fig. S5).

\begin{tabular}{|c|c|c|c|c|c|c|}
\hline \multirow[b]{2}{*}{ z_Republican } & \multicolumn{2}{|c|}{ Model 1} & \multicolumn{2}{|c|}{ Model 2} & \multicolumn{2}{|c|}{ Model 3} \\
\hline & -0.35 & $(-12.54)$ & & & -0.21 & $(-7.74)$ \\
\hline z_Conservative & -0.19 & $(-6.93)$ & & & -0.07 & $(-2.44)$ \\
\hline Hierarchy & & & -0.47 & $(-21.52)$ & -0.33 & $(-13.12)$ \\
\hline Individualism & & & -0.30 & $(-13.92)$ & -0.24 & $(-10.75)$ \\
\hline Constant & 0.00 & $(0.87)$ & 0.00 & $(0.99)$ & 0.00 & $(0.91)$ \\
\hline$R^{2}$ & 0.24 & & 0.31 & & 0.35 & \\
\hline$F$ & $(2,1537)$ & 244.35 & $(2,1537)$ & 327.53 & $(4,1535)$ & 201.84 \\
\hline$\Delta F$ & & & & & $(2,1535)$ & 51.64 \\
\hline
\end{tabular}

Table S6. Impact of political orientations and of cultural worldviews on climate change risk perceptions. $N=$ 1540. The effects of the model predictors are expressed in unstandardized OLS regression coefficients with $t$ statistic indicated parenthetically. The outcome variable is the standardized (z-score) response to GWRISK. Bolded indicates that the coefficient, $F$-statistic , or the change in $F$-statistic is significant at $p<0.05$. Missing values were replaced using multiple imputation ${ }^{18}$.

This reflects the greater precision of the cultural-worldview measures in identifying sources of variance within the sample. Adding cultural-worldview measures to a model with political-orientation measures (Table S6, Model 3 vs. Model 1) increases overall explanatory power by approximately 50\% $\left(\Delta R^{2}=0.11, \Delta F\right.$-statistic $\left.(2,1535)=51.64, p<0.01\right)$, whereas adding the political-orientation measures to a model with cultural-worldview measures (Table S6, Model 3 vs. Model 2) increases explanatory power by only $13 \%\left(\Delta R^{2}=0.04, \Delta F\right.$-statistic $\left.(2,1535)=26.67, p=<001\right)$. 


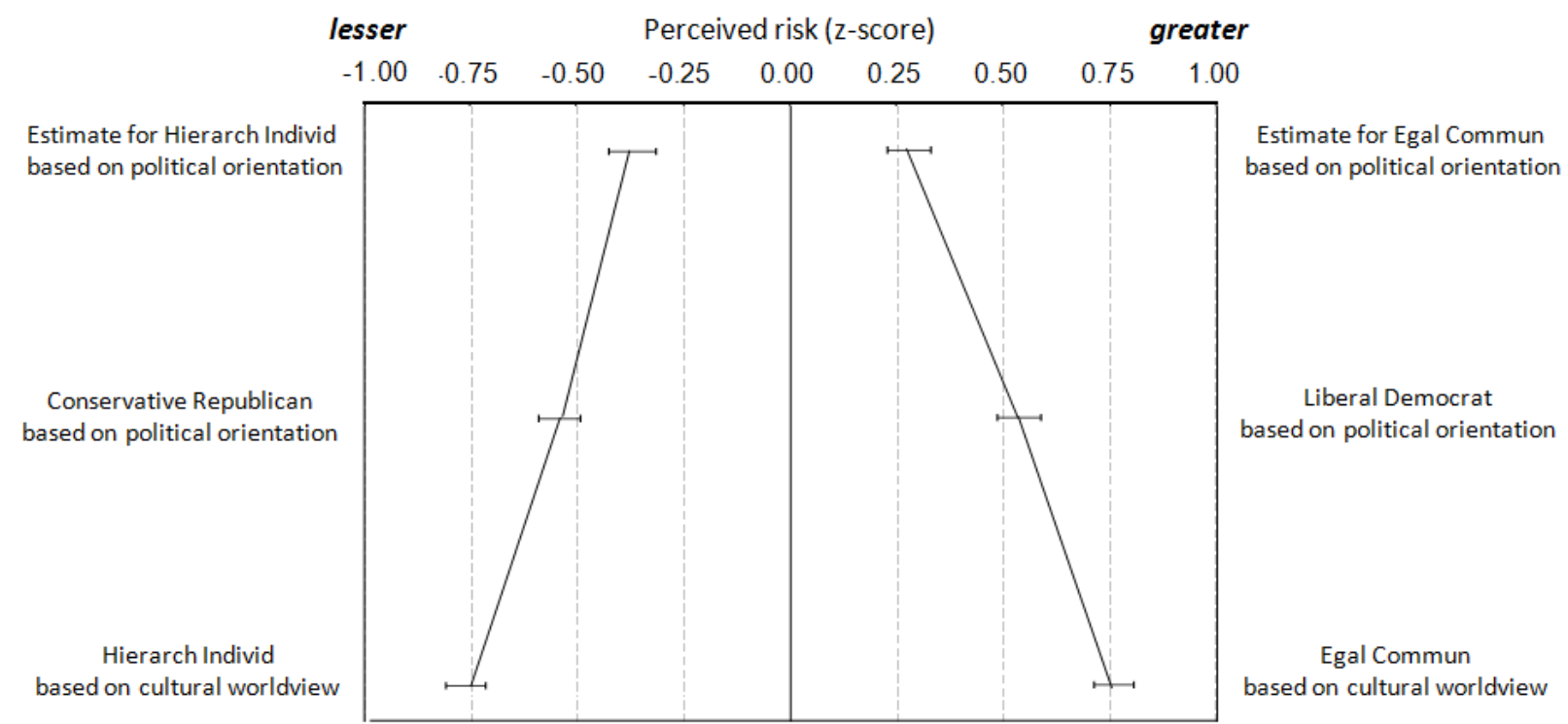

Fig. S5. Comparison of dispositional measures of climate-change risk perception. Point estimates are response to GWRISK risk-perception item (converted to z-score). Comparison of “Conservative Republican” and "Liberal Democrat" sets the values for both CONSERV and REPUB at $-1 S D$ and $+1 S D$, respectively (derived from Table S6, Model 1). Comparison of "Egalitarian Communitarian based on cultural worldview" and "Hierarchical Individualist based on cultural worldview" sets the values for Hierarchy and Individualism at $-1 S D$ and +1 SD, respectively (derived from Table S6, Model 2). Comparison of "estimate for Hierarch Individ based on political orientation" and "estimate for Egal Commun based on political orientation" sets the values for REPUB and CONSERV at mean scores of Egalitarian Communitarians and Hierarchical Individualists on those measures, respectively (derived from Table S6, Model 1), and hence represents an estimate of how divided individuals with those cultural worldviews would be if one lacked information about their cultural worldviews and had information only about their political orientations. CIs indicate 0.95 level of confidence.

c. Science Literacy and numeracy. We also created parallel models to examine whether the political-orientation measures, like the cultural-worldview ones we used in our study, interact with Science literacy/Numeracy (Table S7). They do.

Because results for analyses performed separately for the two risk perception measures generated near-identical results, we present a single analysis based on ENVRISK, a composite environmental-risk perception measure formed by summing the $z$-score responses to GWRISK and NUKERISK ( $\alpha=0.57)$. 
We then constructed parallel models in which, first, Science Literacy/Numeracy plus the relevant dispositional variables — the cultural-worldview measures or the political-orientation measures—and, thereafter, cross-product interaction terms were entered in sequence.

Table S7, Model 1 reproduces the results featured in the main text. Controlling for Science Literacy/Numeracy (Table S7, Model 1(a)), both worldview predictors strongly predict reduced concern with environmental risk. Both cross-product interaction terms (Model 1(b)) are significant and have negative signs, indicating that as Science Literacy/Numeracy increases, the risk-skepticism associated with Hierarchy and Individualism (and correspondingly the risk-sensitivity associated with Egalitarianism and Communitarianism) increase.

Model 2 shows similar results for the political-orientation variables. Both political orientation measures strongly predict reduced concern with environmental risk even controlling for Science Literacy/Numeracy. The cross-product interaction terms are both negative. Although z_Sci/num $x$ REPUB is not significant on its own $(b=-0.04, t$-statistic $=-1.31, p=0.19)$, the significant change in $F$ statistic confirms that the joint effect of the cross-product terms is ${ }^{19}$. Accordingly, as respondents Science Literacy/Numeracy scores increase, so does the gap in risk perceptions associated with variance in the political-orientation variables.

Finally, Model 3 combines the two alternative sets of dispositional variables. The culturalworldview predictors explain more variance. The addition of the cultural-worldview predictors to a model containing only Science Literacy/Numeracy and the political-orientation measures increases explanatory power by about $50 \%\left(\Delta R^{2}=0.11, \Delta F\right.$-statistic $\left.(2,1535)=104.84, p=<001\right)$, whereas the addition of the political-orientation measures to a model containing only the cultural-worldview predictors and Science Literacy/Numeracy increases explanatory power by about $11 \%\left(\left(\Delta R^{2}=0.03, \Delta F\right.\right.$-statistic $(2$, 1535) $=22.89, p=<001$.

Model 3(b) adds cross-product interaction terms. All have negative signs. Moreover, although none of the individual predictor coefficients are statistically significant, their joint effect is statistically significant, as indicated by the significant change in the F-statistic for Model 3(b). Accordingly, it can be 
inferred that Science Literacy/Numeracy magnifies polarization as respondents become simultaneously more hierarchical, more individualistic, more conservative, and more Republican, on the one hand, and more egalitarian, more communitarian, and more liberal, on the other. 


\begin{tabular}{|c|c|c|c|c|c|c|c|c|c|c|c|c|}
\hline \multirow[b]{3}{*}{ z_Sci/Num } & \multicolumn{4}{|c|}{$\underline{\text { Model } 1}$} & \multicolumn{4}{|c|}{$\underline{\text { Model } 2}$} & \multicolumn{4}{|c|}{ Model 3} \\
\hline & \multicolumn{2}{|c|}{$a$} & \multicolumn{2}{|c|}{$b$} & \multicolumn{2}{|c|}{$a$} & \multicolumn{2}{|l|}{$b$} & \multicolumn{2}{|c|}{$a$} & \multicolumn{2}{|c|}{$b$} \\
\hline & -0.18 & $(-8.16)$ & -0.19 & $(-8.49)$ & -0.18 & $(-7.67)$ & -0.19 & $(-8.64)$ & -0.17 & $(-7.67)$ & -0.18 & $(-8.14)$ \\
\hline Hierarchy & -0.42 & $(-18.62)$ & -0.41 & $(-17.93)$ & & & & & -0.33 & $(-12.66)$ & -0.32 & $(-12.06)$ \\
\hline Individualism & -0.25 & $(-11.40)$ & -0.25 & $(-11.03)$ & & & & & -0.21 & $(-9.14)$ & -0.20 & $(-8.71)$ \\
\hline z_Republican & & & & & -0.29 & $(-10.27)$ & -0.29 & $(-9.68)$ & -0.08 & $(-5.80)$ & -0.08 & $(-5.88)$ \\
\hline z_Conservative & & & & & -0.14 & $(-4.82)$ & -0.13 & $(-4.41)$ & -0.01 & $(-0.48)$ & 0.00 & $(-0.09)$ \\
\hline Hier x z_Sci/Num & & & -0.05 & $(-2.39)$ & & & & & & & -0.01 & $(-0.44)$ \\
\hline Indiv x z_Sci/Num & & & -0.05 & $(-2.17)$ & & & & & & & -0.03 & $(-1.24)$ \\
\hline z_Repub x z_Sci/Num & & & & & & & -0.03 & $(-1.31)$ & & & -0.04 & $(-1.37)$ \\
\hline z_Conserv x z_Sci/Num & & & & & & & -0.10 & $(-3.57)$ & & & -0.04 & $(-1.31)$ \\
\hline Constant & 0.00 & $(-0.12)$ & 0.00 & $(0.14)$ & 0.00 & -0.03 & 0.02 & $(0.54)$ & 0.00 & $(0.97)$ & 0.00 & $(0.25)$ \\
\hline$R^{2}$ & 0.28 & & 0.29 & & 0.20 & & 0.21 & & 0.31 & & 0.32 & \\
\hline$F$ & $(3,1536)$ & 198.39 & $(5,1534)$ & 121.97 & $(3,1536)$ & 132.56 & $(5,1534)$ & 87.95 & $(5,1534)$ & 132.30 & $(9,1530)$ & 75.62 \\
\hline$\Delta F$ & & & $(2,1534)$ & 5.00 & & & $(2,1534)$ & 16.41 & & & $(4,1530)$ & 3.93 \\
\hline
\end{tabular}

Table S7. Environmental risk perceptions. $N=1540$. The effects of the model predictors are expressed in unstandardized OLS regression coefficients with $t$ statistic indicated parenthetically. The outcome variable is the standardized (z-score) response to ENVRISK. Bolded indicates that the coefficient, F-statistic , or the change in $F$-statistic is significant at $p<0.05$. Note that because all predictors are centered at 0 , the regression coefficients for the predictor and moderator variables in models that contain cross-product interaction terms indicate the effect of the relevant variable when the other is at its mean value ${ }^{17}$. Missing values for individual cultural worldview items, for political orientation variables, and for indicators of ENVRISK were replaced using multiple imputation ${ }^{18}$. 


\section{Supplementary Information References}

1. Streiner, D.L. Unicorns do exist: A tutorial on "proving” the null hypothesis. Canadian Journal of Psychiatry 48, 756-761 (2003), p. 759.

2. Cohen, J., Cohen, P., West, S.G. \& Aiken, L.S. Applied multiple regression/correlation analysis for the behavioral sciences (L. Erlbaum Associates, Mahwah, N.J., ed. 3rd, 2003), pp. 297-98.

3. Cohen, J. Statistical power analysis for the behavioral sciences, (Lawrence Earlbaum Assocs., Hillsdale, NJ, 1988), p. 56.

4. Kahan, D.M., Braman, D., Slovic, P., Gastil, J. \& Cohen, G. Cultural cognition of the risks and benefits of nanotechnology. Nature Nanotechnology 4, 87 (2009).

5. Kahan, D., Braman, D., Cohen, G., Gastil, J. \& Slovic, P. Who fears the HPV vaccine, who doesn't, and why? An experimental study of the mechanisms of cultural cognition. L. \& Human Behavior 34, 501 (2010).

6. Wildavsky, A. \& Dake, K. Theories of risk perception: Who fears what and why? Daedalus 114, 41 (1990).

7. Kahan, D.M., Braman, D., Monahan, J., Callahan, L. \& Peters, E. Cultural cognition and public policy: The case of outpatient commitment laws L. \& Human Behavior 34, 118-140 (2010)..

8. Kahan, D.M., Braman, D., Gastil, J., Slovic, P. \& Mertz, C.K. Culture and identity-protective cognition: Explaining the white-male effect in risk perception. Journal of Empirical Legal Studies 4, 465-505 (2007).

9. Kahan, D.M., Jenkins-Smith, H. \& Braman, D. Cultural cognition of scientific consensus J. Risk Res. 14, 147-174 (2011).

10. Peters, E., Västfjäll, D., Slovic, P., Mertz, C. K., Mazzocco, K., \& Dickert, S. Numeracy and decision making. Psychol. Sci. 17, 407-413 (2006).

11. Peters, E., Hibbard, J., Slovic, P. \& Dieckmann, N. Numeracy skill and the communication, comprehension, and use of risk-benefit information. Health Affair 26, 741-748 (2007)..

12. Lipkus, I.M., Samsa, G. \& Rimer, B.K. General performance on a numeracy scale among highly educated samples. Medical Decision Making 21, 37 (2001).

13. Weller, J., Dieckmann, N.F., Tusler, M., Mertz, C.K., Burns, W., \& Peters, E. Development and testing of an abbreviated numeracy scale: A Rasch Analysis approach Journal of Behavioral Decision Making (in press).

14. National Science Board. Science and Engineering Indicators, 2010. (National Science Foundation, Arlington, Va., 2010).

15. Allum, N., Sturgis, P. Tabourazi, D. \& Brunton-Smith, I. Science knowledge and attitudes across cultures: a meta-analysis. Public Understanding of Science 17, 35 (2008).

16. Berry, W.D. \& Feldman, S. Multiple regression in practice. Sage university papers series. Quantitative applications in the social sciences no. 07-050 (Sage Publications, Beverly Hills, 1985), pp. 41, 48.

17. Jaccard, J. \& Turrisi, R. Interaction effects in multiple regression (Sage Publications, Thousand Oaks, Calif., ed. 2nd, 2003), pp. 15-16. 
18. Rubin, D.B. Multiple imputation for nonresponse in surveys. Wiley classics library (WileyInterscience, Hoboken, N.J. 2004).

19. Judd, C.M. Everyday data analysis in social psychology: Comparisons of linear models. in Handbook of research methods in social and personality psychology (eds. Reis, H.T. \& Judd, C.M.) 370-392 (Cambridge University Press, New York, 2000), p. 373.

20. Gelman, A. \& Hill, J. Data Analysis using regression and multilevel/hierarchical models (Cambridge University Press, Cambridge, 2007).

21. King, G., Tomz, M. \& Wittenberg., J. Making the most of statistical analyses: Improving interpretation and presentation. Am. J. Pol. Sci. 44, 347-361 (2000). 